\title{
A Long-Term Field Study on the Adoption of Smartphones by Children in Panama
}

\author{
Elba del Carmen Valderrama Bahamndez \\ FISC, Technological University of Panama \\ P.O. Box 0819-07289, El Dorado, Panama City, \\ Panama \\ elba.valderrama@utp.ac.pa
}

\begin{abstract}
Computing technology is currently adopted in emerging countries. Especially mobile phones and smart phones become widely used - with a much higher penetration than traditional computers. In our work we investigate how computing technologies and particularly mobile devices can support education. While previous work focused on controlled experiments, in this paper we present the results of a 20 weeks long study of mobile phone usage in an emerging region. Our aim was not only to investigate how the phones are used for education but also to learn how they are adopted by children in daily life. By logging screenshots, we used an unsupervised approach that allowed to unobtrusively observe usage patterns without the presence of researchers. Instead of offering tailored teaching applications, we used general-purpose applications to support teaching and found that the phone itself was an empowering technology similar to pen and paper. Based on a detailed analysis of actual use in a natural setting, we derived a set of typical use cases for mobile phones in education and describe how they change learning. From in-depth interviews with a teacher, selected guardians and pupils we show that introducing mobiles phones has great potential for supporting education in emerging regions.
\end{abstract}

\section{Author Keywords}

Adopting mobile phones; children; education; emerging countries; learning; mobile phones.

\section{ACM Classification Keywords}

H.5.2. Information Interfaces and Presentation (e.g., HCI): User Interfaces

\section{General Terms \\ Human Factors}

\section{INTRODUCTION}

Over the last decade, mobile phones have become the most ubiquitous devices in developed countries. In emerging regions, however, the adoption of mobile phones is even more

Permission to make digital or hard copies of all or part of this work for personal or classroom use is granted without fee provided that copies are not made or distributed for profit or commercial advantage and that copies bear this notice and the full citation on the first page. Copyrights for components of this work owned by others than the author(s) must be honored. Abstracting with credit is permitted. To copy otherwise, or republish, to post on servers or to redistribute to lists, requires prior specific permission and/or a fee. Request permissions from permissions@ acm.org.

MobileHCI 2014, September 23-26, 2014, Toronto, ON, Canada.

Copyright is held by the owner/author(s). Publication rights licensed to ACM.

ACM 978-1-4503-3004-6/14/09 ...\$15.00.

** DOI STRING ***

\author{
Bastian Pfleging, Niels Henze, \\ Albrecht Schmidt \\ VIS, University of Stuttgart \\ Pfaffenwaldring 5a, 70569 Stuttgart, Germany \\ \{firstname.lastname\}@vis.uni-stuttgart.de \\ \{firstname.lastname\}@vis.uni-stuttgart.de
}

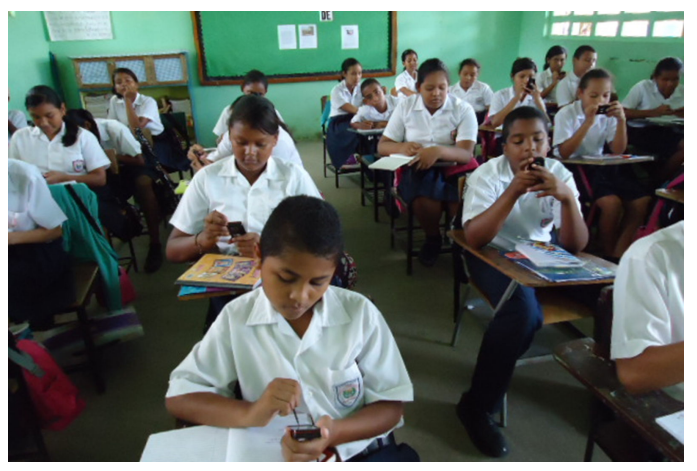

Figure 1. Children in class working with their phones.

disruptive. They are often the first computing platform that people get access to. In our previous work we investigated how mobile phones and smart phones can be used to support education in developing regions. Offering high quality education in rural areas of emerging countries is difficult.

The use of computers to support education has been proposed over the last decade. Experiments with computer labs have been conducted and the idea of one laptop per child (OLPC $\left.{ }^{1}\right)$ has been explored. The use of conventional computers has been less successful than many expected. The usage model (e.g., a computer lab), as well as the administration and maintenance of computers in schools has made widespread and sustained use difficult. New devices are costly; hence, economic constraints often prohibited their uptake.

Recent projects have observed that mobile phones and in particular smart phones are a viable alternative to conventional computers. Over the last years mobile phones have become ubiquitous around the world and the dominant computing platform in many emerging regions. Research has shown that phones can provide myriad opportunities to support teaching and learning activities. However, previous work mainly focused on rather short and supervised deployments. Studies were highly supported by the researchers, who provided exciting new teaching material.

In this paper we report from a long-term study that we conducted to not only understand how mobile phones are used as teaching and learning tools but also to learn how they are adopted in daily life. We conducted a 20 weeks long study
${ }^{1}$ OLPC. Last access: 2014-02-21, http: //one laptop.org/ 
with school children in a small town in rural Panama. We aimed at learning about the opportunities and challenges that arise when phones become available as personal tools.

In our study a class of 23 pupils aged 10 to 12 were equipped with simple touchscreen cell phones (see Figure 1). The children were required to bring their phones to school every day, but they could also use them in their spare time and take them home. During the study, almost no on-site support by the researchers was given and the teacher was completely free in the way he used the phones in his teaching. In order to understand how children used the phones and how they were integrated with the teaching we automatically recorded time-stamped screenshots every 20 seconds on each phone (while being in use). By using parts of the about 1,663,000 screenshots we analyzed how the children used their phones for learning and recreational activities.

Additionally, we conducted extensive interviews with teachers, children, and selected parents to understand how phones impacted them in teaching, learning, and their lives. Our results suggest that phones are a very useful and versatile tool for a variety of different subjects and tasks in schools. For the pupils, the phones provided new and efficient ways for information gathering and also became an alternative to copying machines, which are not available in the school. For the teacher it became apparent, that once accustomed to the availability of the phone as a tool, there was little to no extra effort in utilizing the phones across many school subjects.

The main contributions of this paper are:

- A report of the results of a 20 weeklong unsupervised study of mobile phone usage in a school in an emerging region.

- A set of typical use cases for mobile phone usage in education based on a detailed analysis of actual use in a natural setting.

- In-depth analysis of responses from children, parents, and a teacher on the impact of mobile phone usage in school.

\section{RELATED WORK}

A large body of work investigates (mobile) learning for children. For stationary devices, various projects such as the "hole in the wall" project [2] investigated how implementation of technology impacts learning. In the following, we focus on work that explored the use of mobile phones for learning in emerging regions. Most authors have analyzed different features of mobile phones for learning like audio [3, 4, 13], image and videos for creating content [11], and learning games [6,8, $9,10]$. In all cases above the approach was to create a learning application or game as a use case. Educational applications that support the curriculum where children can review lessons, play quizzes, and monitor their progress have for instance been explored for teaching in Africa [5, 12].

Kam et al. [8] explored learning games for English language in after-school settings in India; they developed learning games based on traditional games known by children in India [9]. In contrast, Jain et al. [6] explored the use of pico projectors in collaborative learning games. Mathur et al. [11] developed an annotation tool that allows teachers to create content to share with pupils using pico projectors.

Audio recording and playback was also explored for learning. While Frohlich [4] and Reitmaier et al. [13] developed a minimal textual application to support storytelling with adults in rural India and Africa respectively; Ford and Leionen [3] implemented an audio wiki to create and access audio content. The use case was evaluated with high school students in South Africa.

The usage and adoption of mobile phones by children was also explored $[1,7,10,14]$. While Bell et al. [1] and Jarievich et al. [7] explored the adoption of mobile phones in the developed world, Kumar et al. [10] explored the usage of mobile phones in an emerging country. Similarly, we explored mobile phone usage in an emerging country in a previous project where we conducted an exploratory short-term study to explore the adoption of mobile phones by children and teachers in classroom settings in rural Panama [14] . In contrast to the work in this paper, our previous study focused on the adoption of using mobile phones exclusively for learning activities. In addition, the children used the phones only for a very short time in the previous study. In contrast, our current study analyzes the longterm effect on the behavior and adoption of mobile phones in two settings - at school and after-school/at home - as well as both for learning and recreational use. Kumar et al. [10] explored the usage of mobile learning outside of classroom settings. They observed the use of a preinstalled customized application for learning outside of classroom settings with a text logger, while we were interested in the adoption of the mobile phones and not a specific application in both settings inside and outside of the school. In addition, our study was also supported by the analysis of the screenshots. As previous work was mainly conducted in very different cultural, social, and economic settings (e.g., India, [10]), we show how different cultures impact the acceptance and use of technologies for education and beyond.

\section{LONG-TERM FIELD STUDY}

\section{Method and Design}

In order to gain knowledge about how touchscreen phones can become a personal tool at school and at home in an emerging country, we conducted a long-term field study over a period of 20 weeks. The study was conducted with pupils of an elementary school in the Panamanian countryside. Besides studying the opportunities and challenges when touchscreen phones are introduced as personal tools, we also wanted to study longer-term motivational effects.

In contrast to other projects, we did not install specific learning applications but provided and explained some general-purpose applications. To allow an unobtrusive observation and to prevent influences by observing researchers, we impemented an application to generate automatic screenshots of the phones screen to create application usage logs and installed it onto each phone.We did a manual post-hoc analysis of the usage of applications after the study by collecting and looking at the corresponding log files, screenshots, and videos stored on each phone. We especially investigated the usage pattern once 
the children were more experienced by analyzing in detail 10 selected days towards the end of the study. We also conducted open interviews with pupils, the teacher involved as well as with the pupils parents. In addition, we distributed questionnaires to all pupils to evaluate the use of mobile phones.

\section{Participants and Location}

We conducted the study at the public primary school Angelina M. de Tirones in Rio Hato. This school was randomly selected based on voluntary applications during a meeting with 200 teachers from different public schools in Panama. From the applicants, the school Angelina M. de Tirones was selected as a typical public primary school in the countryside of Panama regarding to infrastructure, class size (2-shift school for smaller classes), and discipline (e.g., school uniform). Rio Hato is an average village in the Panamanian countryside. The inhabitants are mainly working as fishermen or service staff (e.g., in hotels) and have a low income. Although located in a rather rural area, the primary school Angelina M. de Tirones is still classified as an urban school. It has about 1200 pupils from grade one to six as well as kindergarten classes. In order to comfortably accommodate all pupils, classes are offered in two school shifts: The morning shift last from 7:00 am to noon $(12: 00 \mathrm{pm})$ while the afternoon shift lasts from 12:30 pm to $5: 30 \mathrm{pm}$. With respect to technology, the school owns a TV set, a DVD player and a computer lab with 12 desktop computers and one video projector. The school has access to the Internet through a portable Internet connection via satellite that is shared via WiFi. However, the signal quality of the satellite link only allows for Internet connectivity when set up near to the computer lab, in the front schoolyard, or at the director's office.

The study was conducted with a 6th grade class (" $6 \mathrm{C}$ ") of the morning shift. In total 23 children (11 male, 12 female) participated in our field study. With the exception of one student (14 years), participants were between 11 and 13 years old ( $M=11.7$ years). Eight children had access to a computer at home that is connected to the Internet; three pupils had access to a computer without Internet connectivity. In contrast to computer ownership, almost all families possessed a mobile phone: 22 pupils reported that their family owns at least one (basic) mobile phone, including four families with a touchscreen phone. Only in one household, a student reported that they do not have electricity at home. Five children had never used a mobile phone before. In contrast, about one half of all pupils (10 pupils) reported to own a mobile phone.

Besides the pupils also their form teacher participated in this field study. He reported that he had never used a touchscreen phone before the start of the study. As primary school teacher in Panama have a rather low monthly gross income (450700 USD), he owned a very low-end phone that only allowed him to make calls and send SMS.

\section{Apparatus}

In order to investigate our research goals, we provided 24 touchscreen phones (Nokia 5530 Xpress Music ${ }^{2}$ ) to all stu-

\footnotetext{
${ }^{2}$ http://www.nokia.com/in-en/support/

product-archive/?action=productArchive $\&$ t $i d=1845426$
}

dents of the selected class as well as to the teacher. This type of mobile touchscreen phones comprises amongst other (general) phone features an integrated video camera, music player functions, and a voice recorder. We did not install any customized learning application on the devices. Instead, we added two general purpose applications to complement to the default features and software set of the selected phone model: The PaintPad ${ }^{3}$ application was installed as a drawing tool and StickyNotes Touch ${ }^{4}$ as another application allowed to write notes analog to post-it notes.

We installed a logging and screenshot application on each handset in order to have a better insight in how the children use their mobile phone. This application includes a screenshot application, which automatically takes a screen shot of the active screen every 20 seconds while the phone is in use. The screenshots are then stored on a SD card. During the study, these cards (and the phones) were collected four times in order to retrieve and centrally store all screenshots and to empty the SD cards afterwards. Similar to the screenshots, the logging application also creates log files containing time stamps and the currently active applications in order to continuously $\log$ the use of the phone. Each time a new application is started, a new $\log$ file entry is generated. Besides allowing a detailed analysis of the phone usage of every pupil, a second goal of the application was to prevent inappropriate use, which could have been revealed by looking at the screenshots.

\section{Participants Consent}

During the initiation phase of our study, we contacted the schoolmaster of the school via e-mail in order to get the permission to conduct the study at his school. Once we had received the permission, the schoolmaster introduced our experimenter to the corresponding class teacher and class. Being in class, the phones were presented to the students. First, the phones were only handed out for in-school use, but only during times when the teacher requested to use the phones. The pupils were allowed to explore every feature of their phone. They were warned to properly use the phone: The experimenter explained to the children that the logging application will posthoc allow the researcher to see any activity on the phone, and that inadequate behavior and use will thereby be revealed to teachers and parents. Within the first days of the study, a meeting was held with the schoolmaster and all parents. During this meeting, the purpose and procedure (including the logging application and process) of the project were presented to the parents. An explanatory letter about the project was handed out to the parents, which also contained a consent form that - once signed - allowed the pupils to participate in the project. Once the consent form had been signed, the children were allowed and encouraged to also carrying and using their phones outside of the school during their spare time. During their spare time, the children were allowed to use their phones for any purpose.

\section{Procedure}

Besides the general introduction of the phones, certain features of the phones were explained throughout the course of

\footnotetext{
${ }^{3}$ http: //mobile.zensis. com/showproduct . php?pid=117

${ }^{4}$ http://store.ovi.com/content/14200
} 
the study: On the first day, when the phones were initially handed out to the students, the video and photo recording and playback functionalities were shown and discussed. After two weeks, the PaintPad application was introduced. The experimenter in class demonstrated another week later how the pupils could use Bluetooth to connect phones and share objects. Using the Internet was neither explicitly explained nor did the phones come with a SIM card. Throughout the study, technical issues were solved either via e-mails between experimenter and teacher or by the experimenter visiting the school and fixing problems in situ.

The study started in May 2012 and ended 7 months later in November 2012. Initially, the study was only planned from May to June but was extended due to the positive experiences teachers and pupils had during the first two months. As the size of the SD cards limited the storage of screenshots, the SD cards and phones had to be collected four times throughout the study. It took about one week each time to empty the SD cards. Also, the Panamanian vacation schedule contains quite a few holidays that resulted in phones being only used at home or on vacation during these times. Holidays were from June 4, 2012 to June 10, 2013 and from September 10, 2012 to September 16, 2012. Additionally, November is traditionally a month with many holidays, extra activities and celebrations outside of the ordinary school life. All together, the phones were used for 20 weeks, including 16 weeks with school days. In November, the experimenter collected all phones. Besides four SD cards (damaged or lost), all phones were returned without a single phone being lost.

\section{Ethical Considerations}

Using the screenshot logger application to collect usage information actually means that sensible private data is recorded. We explained to all the persons involved in our study (teacher, principal, and in particular parents and students) how the screenshot logger application works and which data is collected. We followed the required steps for conducting research with school children in Panama and we followed the policies and regulations of the involved institutions.

\section{ANALYZING PHONE USAGE}

Based on the large sets of screenshots that were recorded we are able to analyze how children used the phones over the course of the study. Overall, about 1,663,000 screenshots have been taken that documented the phone usage. Figure 2 shows typical screenshots that have been observed. As screenshots were taken every 20 seconds, longer interaction periods with the same application resulted in several images of the same application that allow seeing which progress in a task or game was made. For applications that were used shorter than 20 seconds it may be the case that no screenshot was recorded. In this case, only an entry in the log file existed. We especially analyzed (manually) about 200,000 screenshots and logs of 10 selected days toward the end of the study period. In our analysis we were interested in:

- Identification of main use cases of the phone at school

- Identification of main use cases at home (educational and recreational)

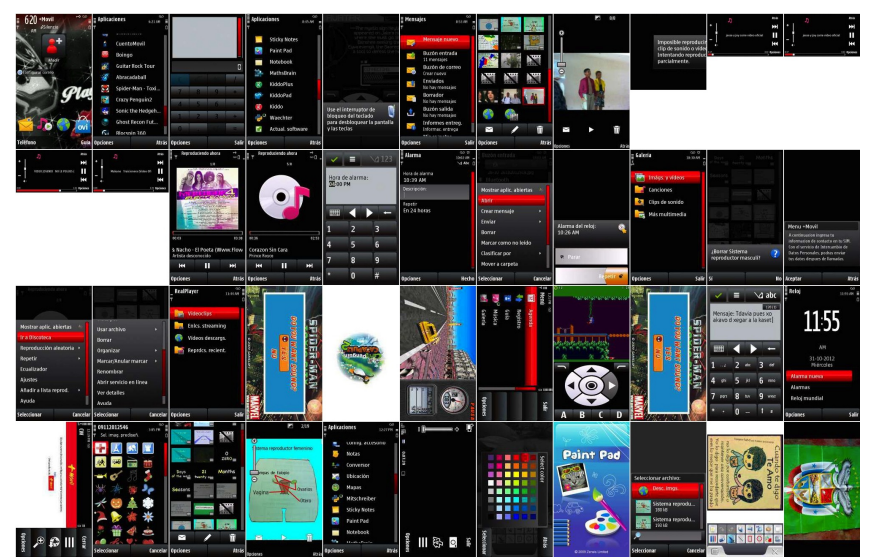

Figure 2. Sample screenshots that were automatically taken on one of the pupils mobile phones for a post-hoc analysis. The picture shows the usage of different applications.

- Long term changes in the use of the phones

- Comparison between users over the time of the study

The analysis was conducted manually by inspection and interpretation of the screenshots.

During the field study the teacher did not receive instructions on how to use the phone or in what context the phone should be used. From the very beginning of the study we could observe that the teacher incorporated the phone as a tool in his teaching approach. In our initial briefing with the teacher and the students we did not provide information on how to access the Internet through the phones. Getting online and accessing the Internet using the school infrastructure was discovered by children from sixth grade, who explained it to their teacher. The teacher took this up and immediately started to use the phones for information gathering in class. In our conversations during the study he stated that he found access to Internet in the classroom the most useful function of the mobile phone, which impacted the way he could teach. He designed more and more learning activities in which the children should use the phone to gather information from the Internet.

Within the classroom there was only limited connectivity and, hence, most of the time the teacher allowed the pupils to access the Internet from the schoolyard where the connection quality was better. Even though the bandwidth of the Internet connection at the school was very limited, it provided a tolerable speed and experience when using mobile Internet on a phone.

We provided the phones without SIM cards. As the pupils were allowed to take the phones home, some of their parents bought prepaid SIM cards to use the phone as well as to have mobile Internet access (about 1US\$ for $500 \mathrm{MB}$ ). At the end of the study, about $16 \%$ of the participating children used mobile Internet with a prepaid card.

In our analysis we identified the following major actives that occurred throughout the study: information gathering using online sources, image capture as replacement for a copying machine, imanipulation of captured images, iusage of the 


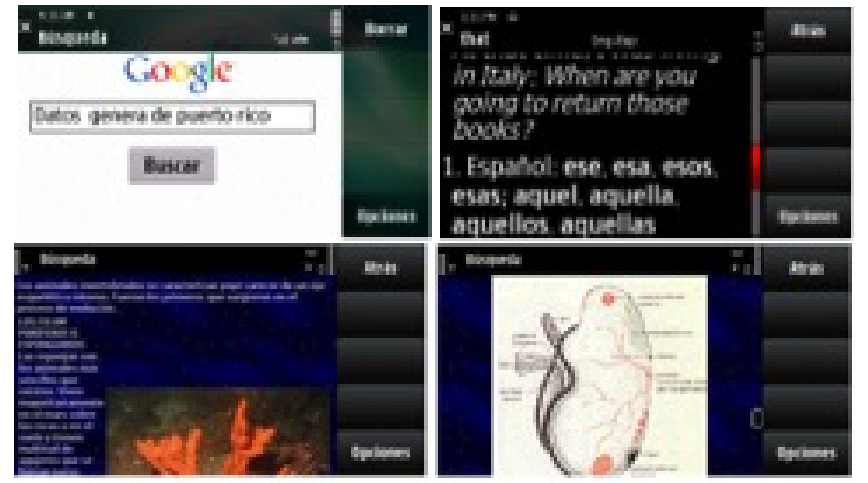

Figure 3. Examples of typical tasks done during a lecture (top left: information gathering task; top right: dictionary use; bottom: information gathering on the web

phone as a tool, listening to music, and playing games. In the remainder of this section we discuss these activities in detail. We also observed that watching and recording videos with the phone was a major feature used for teaching and learning. We will discuss this in the following section.

\section{Information Gathering}

Once all children understood how to access the Internet on their phone, this feature was widely used across different subjects. From the screenshots we could observe that information gathering tasks were done in the following subjects: In Spanish the tasks were to get information about prepositions, conjugations and accents. In Natural Sciences pupils received an open task to learn about invertebrates. In the context of Religion the tasks included finding a list with the 10 commandments. A further example task was to find details on the history Panama Canal as well as images. The information sources used by the pupils were very diverse and contributed according to the teacher to the discussion in the classroom. In Figure 3 screenshots from different information seeking tasks are displayed. During the Olympic Games 2012 students used the phones to get news about the events. The teacher took this as an opportunity to discuss the event with his pupils.

Overall, the phone provides an easy means for individual Internet access for pupils. Looking for information on the phone is cumbersome, but sufficient in many situations. Over the course of the study the use of the phone for searching information increased and pupils made use of this function to suit their personal information needs both in the context of education as well as for recreation.

\section{Image Capture}

As reported in one of our previous papers [14] multimediaenabled phones allow pupils to use the camera to capture worksheets and fill them out virtually by using a paint application. In this study, we were able to observe this usage pattern again. The convenience of this approach seems to be a main driver. The teacher does not need to prepare work sheets but can directly use material from books and the children can capture this content on their devices. This approach is especially important for differentiation. For instance, if a child has already finished a given task this method allows the teachers
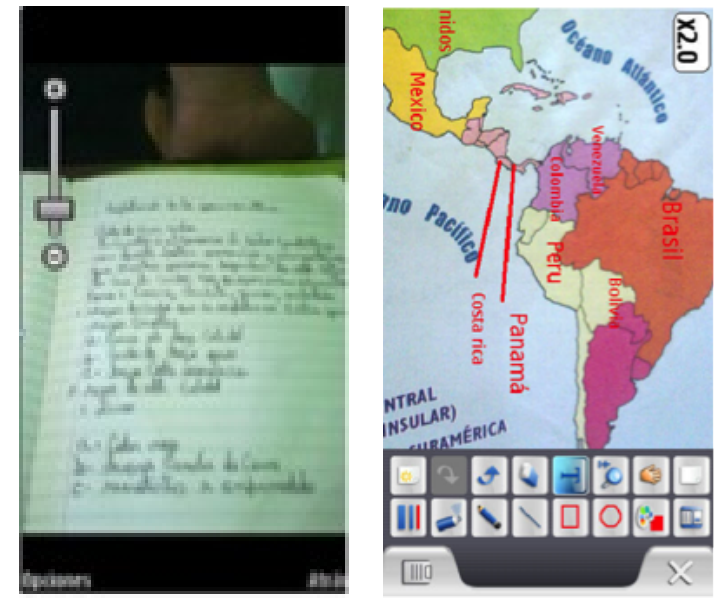

Figure 4. Images captured with the phones camera. Left: copying written notes; right: annotating a captured map

to provide additional material with more challenges to such students.

From the screenshots we collected during the field study, we found that eight pupils used the camera phones to take pictures of books, blackboards, and classmates annotations and notes. When asking the children about the images there were different reasons for capturing content. Photos of the blackboards were taken by children who expected that this information would help them with their homework. When one child was away from class, photos of the black-board and of certain written notes (e.g., a text written by the classmate, see Figure 4) were taken to allow the child to rework what happened at school.

We also saw that children used the camera of the phone to take photos when they forgot books at home that they were required to work with in class.

Before the use of the camera, children typically had to copy the written information by hand. In general, all these cases show that the phone replaces the function of a copying machine, which is not available at this particular school.

\section{Manipulation of Captured Images}

The most common step after capturing a photo of a worksheet or a form was to use the installed image manipulation software Paint. Using this app, the pupils were able to digitally fill in missing numbers or words into worksheets and cloze tests. Obviously, well-equipped schools either use (physical) workbooks or the pupils receive actual copies to fill in the missing elemenst. If this option is not available, as in the case of the school in Panama we worked with, having the opportunity to capture images and fill out forms digitally is a welcome alternative. This is especially helpful for math as this increases the number of tasks a student can solve compared to the situation where they have to copy the tasks first. Figure 4 shows an example of a captured and annotated map.

We observed that children preferred to use the virtual keyboard to fill out cloze tests or forms (manipulating photos taken of book exercises), rather than filling them by handwriting. In our interviews, the pupils stated that they would like handwrit- 
ing as input modality if the writing would be digitized and converted into text.

\section{Usage of the Phone as a Tool}

From the screenshots we see that the children often used the calculator application, especially to support them to when calculating with negative numbers. Further tools employed were dictionary and translator applications (Figure 3).

\section{Listening to music}

During the ten days that we analyzed in detail, the maximum time a child listened to music on one day was 167 minutes (min.: 0 minutes). The average daily listening time differed between 18 seconds/day and 128 minutes/day among the pupils. In that time the children listened to 808 songs (771 in Spanish, 36 in English, one in Portuguese). Although the number of songs downloaded was quite high, only 20 songs were commonly listened to and downloaded by almost all children. The children mainly listened to Latin American music. Furthermore, all children had at least one religious song on their phone, one child only had religious songs.

The pupils shared the music they downloaded from the Internet with their peers using Bluetooth. The transfer of files was usually done at school, either early in the morning before class or during the morning breaks.

\section{Playing Games}

Based on our detailed analysis (10 days), the children spent on average between one and two hours per day on playing games. In most cases they played at least three different games. Most of these games were downloaded from the Internet. With this regard, we found interesting gender differences: Most girls downloaded the same games. Therefore they were able to interchange information about games they had downloaded. In contrast, most of the boys downloaded different games. Furthermore, girls played different games than boys. While boys preferred to play action games, girls preferred to play adventure games. The most popular game played by girls was WonderZoo ${ }^{5}$ where the player has to uncage locked up animals. To our surprise, during the days we analyzed girls spent more time on playing games than boys. Only four of children actually played some kind educational game (e.g., arithmetic trainer / English trainer) during the analyzed period.

\section{Non-Educational Pictures and Images}

Taking photos was one of the main activities done by the children. We analyzed the pictures taken by all children that were not part of some learning assignments. The children took a variety of pictures that we classified by using the following categories:

- People: photos of family members or friends, teachers or classmates, and pictures of the children themselves.

- Nature: photos of animals in their environment like dogs, chicken, horses, but also picture of the landscape

- Sport: pictures related to their favorite football team.

\footnotetext{
${ }^{5}$ http://www.gameloft.com/mobile-games/wonder-zoo/
}

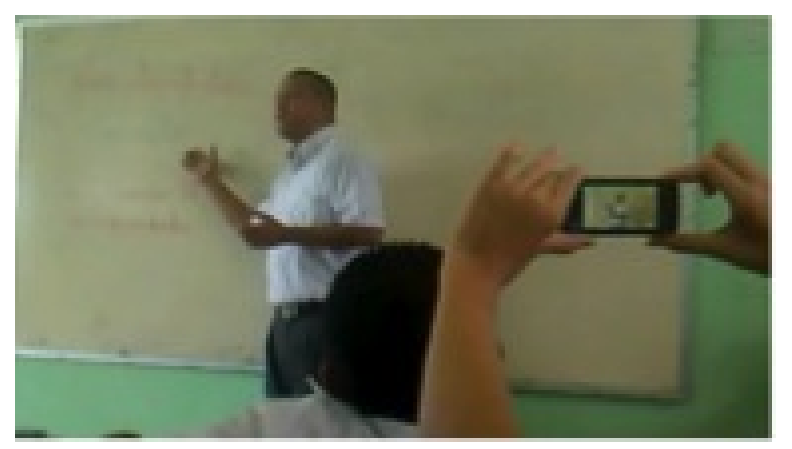

Figure 5. Example use of mobile phones at school: A student records an explanation of his class teacher.

- Other: objects photographed like cars, bikes, etc. This also includes pictures of hand-made drawings and paintings.

- Religion: images related to Christianity.

- School related: pictures of books, blackboards, events, and contests at school

The main topics photographed by boys and girls were family/friends, either at home or during special events. Selfportrait photos were more common for girls than for boys.

With respect to images downloaded, the most frequently category found were friends and love messages (e.g., a teddy bear with hearts), followed by showbiz (e.g., singers) and religious images. Photos of singers were especially shared using Bluetooth.

\section{Video Recording and Playback}

When categorizing videos filmed at school, we distinguish between different recording settings: Individual shooting in this case refers to one child filming his/her own video. In contrast, a class shooting refers to the situation when all children simultaneously film the same object. Accordingly, in a collaborative shooting children work together, e.g., when they were acting. For videos filmed at school the children preferred individual and group shootings compared to collaborative shootings. The reason is that filming in teams collaboratively and simultaneously was not suitable inside the classroom. There are children who speak loud and those who speak more quiet. For instance, dialogs to be recorded by one team group can accidentally be captured by a different group and overlapped the own voice of the latter group. As the school selected for our study does not have a big garden, such student teams could not go outside and create videos without interrupting other grades. A very common approach among the students was therefore to simply film the teachers explanations (Figure 5) in order to play them back later at home. Also, the teacher requested the children to record films at home.

\section{Video Playback}

As children already had the experience of watching educational videos in the computer lab, we asked them to compare watching videos on a computer to wathing them on a mobile phone. Most children stated that they prefer watching videos on the phone because it is more accessible. P\#1: "The videos 
are easier to find." P\#3: "On the PC I forget where to find the videos." P\#4: "I can find the videos faster." The children also reported that it gives them freedom: "I can see the video as long as I want."(P\#2) "I can replay a video until I really understand the subject."(P\#1) "I can watch the video again the other day."(P\#6) "I can watch the video without time pressure.”(P\#10)

Mobility was another reason why the children preferred to watch videos on the mobile phone rather than on a desktop computer: "I can see a video at any place I am in contrast to PCs [that] are difficult to carry," "It easier to carry with me." Concentration was also mentioned as a factor for preferring mobile phones to watch videos. "[It] helps me to memorize." "I can concentrate more." "I can learn more." The reduced screen size and resolution of a phone displays was the main complaint of the children with regard to watching videos on mobile phones: "I can see the video bigger and clearer [on the computer screen]". A few pupils did not prefer one solution over the other.

\section{INTERVIEW WITH A TEACHER}

Three months after starting the study as well as at the end of the study we conducted open interviews (30 minutes each) with the form teacher. In these interviews, we addressed the following topics: impact on teaching and learning, discipline and motivation, effect on interaction between children, opportunities that arise with phones in the classroom, and finally risks and how to deal with them. In the following we report some of the insights that were most interesting to us. We have to point out that the teacher knows his pupils quite well as he had been teaching them for three years.

\section{Motivation to Learn}

Just before the field study, three pupils of the selected class (it had 25 pupils before) showed a peculiar behavior. They did not show up regularly at school and showed a bad behavior at school. The teacher reported: "I have students with really serious problems at home, like parents in jail because of drugs, [...] who show a bad behavior and a bad performance in class." In fact, two of them finally left school permanently. The third student instead changed his behavior with the begin of the study. According to the teacher, this person showed a radical change in his behavior, attended the classes regularly, and became much more active in class. "[The student] has made a 180 degree change, at the beginning of the school year he was undisciplined, did not attended classes, did not do assignments, etc. Now he started to be more engaged at school, improved his grades, and finally passed the exam to continue to grade seven. And I think that the use of a mobile phone has positively influenced this change."

The teacher also noted a change in the conduct of his pupils: "There was a positive change. Students who were not used to participate in class or work on assignment, $[\ldots]$ one [could] see them working and being engaged in the learning tasks... Students who were timid and did not ask questions $[\ldots]$ started to put their hands up."

\section{The Phone as a Tool for Learning and Teaching}

When asked about what features the mobile phone needs to have to be the perfect tool for learning, the teacher answered that "it would be the possibility to have a good Internet connection available, a good antenna, that allows downloadind information and educational videos faster without the need to buy mobile Internet or to move to the front yard. This would be perfect. We used the Internet several times but the Internet was very slow and inconsistent [unreliable]. Mainly those kids who paid [mobile Internet] get better access to it... With all these phone companies in Panama, could not one of them install a good Internet antenna at school? "

Internet for mobile phones was considered as a very useful tool for learning: "Children can gather Information about the topic we are introducing and discussing $[\ldots]$ or they can look for videos and then download them to their phones and watch them later, it is simply fantastic."

As a final note, the teacher underlined the increase mobility of the phones: "[...] if I could give a mobile phone to each child instead to a computer... it would be easier to transport... The student has direct access to the information in his/her pocket, $\mathrm{s} / \mathrm{h}$ e do not have to move [to the lab] and does not to have to install all these tools and it would be more pragmatic. You look for something, store it, and you can review it whenever you want to."

\section{Multigrade Schools}

In very remote regions of Panama with less population, one can also find multigrade school, i.e., schools where one teacher is teaching a class consisting of pupils from different grades at the same time. We also wanted to know if it would be possible to use phones in such schools and classes as well. When asked about such schools, the teacher first explained his experience on such a school:

"I was a multigrade teacher for about 10 years, I worked with a tribe in the mountains[...]. This is a community that lives in extreme poverty [...] under inhuman conditions. I had 20 to 25 students from three [different] grades together ... I had to be like MacGyver... This tool in multigrade schools will be incredible because we can assign a task to each child to develop while the teacher attends the other group. [Mobile] phones can support the teacher to better manage and distribute learning task according to age similar to the approach followed in multigrade schools."

When we asked further about the access to technology and electricity he answered: "To arrive there you need two hours by car with four-wheel drive and during winter, instead of the car carrying people, people have to carry [push] the car... People there have simple cell phones and there is signal [network coverage]... And nowadays I hear it has electricity."

\section{Social Impact}

The use of mobile phone caused other positive social effects to the pupils behavior. Usually, only the child with the best grades gets awarded or is considered to take part in special or new academic projects. As we distributed a phone to every child, pupils felt that they were equally important and included 
by the school regardless their academic profile. The teachers underlined this positive effect and commented:

"The pupils feel more motivated and with a higher commitment to work with mobile phones as they feel themselves important. This arouses their responsibility to take care of the phone... No phone got damaged or lost." Also, the use of mobile phones seems to be also influenced in the engagement in non-academic activities done at school. As the school has a large number of students, it is often selected to participate in contests or other extracurricular activities. In those cases, not all children participated in former times. Reasons to not doing so were related shyness or because the kids simply did not want to.

"X. is a girl who never participated [in such activities], I mean, she is good academically, but she does not want to participate in external activities... She [only] cares to get good marks ... I have told her mom, education is more: Behavior, performance, and attitude. It is not [the] only [goal] to have the best marks. [...] N.N. is the best student [academically] of the whole school, but she is a very timid girl, and she does not participate in extra activities. But the main problem with her is that she is too quiet, and shy... I organized an activity where students had to give a speech about moral values in groups of four to children of lower grades who attended also classes in the morning. [...] I always did these extra activities at school, but now I wanted them to do it. Using the phone to record a video, watching the video, one can see the qualities everyone has [...] We have [students with] outstanding voices... I wanted them to go to the other class and see that it is not easy to get other children to pay attention to whom is talking in front ...I accomplished for the very first time that X. participated and $\mathrm{N}$. overcame her shyness."

Recording videos was a way that the teacher considered as helpful for children to lose their shyness about talking in public. "Some pupils look nervous when they film and then watch the video showing themselves... [They realize] it is normal that everyone needs to get rid of the fear to talk in front of an audience. [...] But the engagement has been high..." In addition he could observe that "[s]tudents also have improved a lot [with regard to] their self-confidence".

However, the teacher will not recommend using phone every day for teaching: "I would use the mobile phone [only] two days a week [...] Part of maintaining the childrens motivation for learning is to vary between activities. Therefore I assume that using [it] daily will considerably decrease the motivation and engagement of the children."

\section{Discipline}

Filming has helped the teacher to witness and control the behavior of problematic students as he explained: "Although I have no discipline problem with most of my pupils, there are two pupils who are tremendous... When I complain to their parents or guardians on how they sometimes behave at school, their parents do not believe me. They think their kids are godsend [...] The other day I used the [mobile phone] camera and filmed one of them while he was fighting against a child of another group before I proceeded to separate them.
When I showed the video to his grandmother she was deeply shocked. [...] That was the last fight."

The students learning discipline also improved by using mobile phones as the teacher explained: "Definitively the discipline is the first that thing improved, when the student works with the cell phone s/he is completely concentrated [...] doing the assignment, or watching a video."

He also talked about the importance for teachers to know the latest technology: "Teachers should adapt to the [new] time [...] Sometime we [docents] say I do not like that, but we have to keep up-to-date ourselves [...] The Pupils already known all these technologies and if not they are fast in adopting them. We teachers have to keep up with the children in the use of technology."

\section{Supervision at Home}

With regard to letting the pupils use their phones at home, the teacher would recommend usage with caution and clear rules: "While I found the use of mobile phones for learning an excellent tool, I think their use at home needs to be controlled. At school, teachers can easily control who is working and who not. However, there are bad addresses [inappropriate web sites] that children should not have access to. Parents should carefully supervise the proper use of the phone as with any other technology. But the main problem is rather than some parents do not supervise what their children do at all."

When asked if we provide with mechanisms that parents set what children access he answered to us: "I do not think that any technical mechanism can help parents to manage what children access on the web because simply parents do not know about technologies [...] In fact, also the parents have a low level of education."

\section{INTERVIEWS WITH CHILDREN}

In order to understand the pupils' opinion on using mobile phones at school and at home, we conducted a group interview with all students. We wanted to know their impressions of using a phone during the study in general and the use of applications in specific. Due to time constraints it was not possible to do individual interviews. In order to minimize any bias due to group influence, we distributed an open questionnaire to each participant that had to be completed and returned the same day and before the interview.

The children stated that there was no problem with learning how to use the phone. This is consistent to what we observed in the screenshots analysis: "Although it was the first time I used a cell phone [...] it was easy to work with the phone. $[\ldots]$ No function was difficult to use for me [...]."

The children admitted that they mainly used their phones for recreation at home: "At home I used the phone to get [download] and listen to music I like." "Racing cars was my favorite game, I played almost every day." "After having done my homework I watched photos [on the web] and [listened to] songs of Prince Royce [teenager singer]. The best photo I put on the screen [as a wallpaper]." 
Also, the children used the phones as status symbol: "Now I can show my friends that I also have a music player." In fact, only 3 participants owned a real MP3 player. Another pupil added: "When I was bored at home I looked for new games to play on OVI [...] Then I showed them to my friend the other day."

The experience of painting was mainly received well by the pupils: "Painting with a phone [i.e., Paintpad application], is similar to painting with pencils only that here I can erase something without holing the paper." Further the students liked that they "can change colors while painting". However, other children preferred traditional painting due to being more creative or having more freedom.

The children found it useful to video record own presentations; some comments received were: "[Giving a live presentation in the classroom] makes me nervous and [I] make mistakes", "in front of others I get nervous and forget everything what I have to say", "[by filming my presentation] with the mobile phone I do not get nervous", "it is important to use new technologies" and "if I forget something I can record the presentation again".

\section{INTERVIEWS WITH PARENTS / GUARDIANS}

At the end of the study, we discussed the concept of using mobile devices with 13 of the children guardians (all female relatives; either mothers, grandmothers, or aunts). Although we tried to have a lively conversation, they were rather timid. Only six of them engaged a little more with us. We think that the shyness is due to their low schooling, and that they are, in case of older women, technology illiterate. However, only one woman did not own a mobile phone. Their main concern was the loss of a device: "My main concern was that the mobile phone gets lost and that I have to pay for it." ' $t$ is an expensive phone [...] so I warned my daughter to really take care of it. [... I I was always watching that she took care [of it] properly."

They were also worried about a proper use of the mobile phone: "In the news they always show the risk of young children when using such technology improperly. I was worry about a bad use of this device, is there a way to control [access to the] Internet?" Another guardian stated: "I find it positive and like that N.N. did assignments with more enthusiasm than before. But I dislike how addicted he became to the device. I have to forbid usage while we eat."

One guardian also commented on the social impact of the use of the phone: "I observed a new attitude and behavior of my grandson at home and at school. He was motivated to attend classes, an engagement that was not there before the [study]." Later we figured that she was actually talking about the child who almost had left school forever.

Also, one participant commented how surprised she was about how fast their children adopted the technology and how they learned from them: "I tried to help my child to film a video at home, my child explained everything in detail although he has never had such a modern phone before. This really impressed me [...] how fast kids learn new technologies.'. As a response, one mother added: "My daughter taught me how to use Bluetooth on my phone."
The fact that all children were considered for the study was also pointed out by one mother: "Finally all children and not only the best pupils were considered to take part in the project. They usually only award children with good marks[... I I think that all children should receive the same treatment."

Using a projector, we showed some examples of the content created by the class while using the phone. "I am still surprised that all this can be created with modern phones. It is amazing!"

\section{LIMITATIONS}

As the study was conducted in a natural environment with no researcher present for most of the time we based our findings on the automatically recorded screenshots as well as on interviews conduced in the middle and at the end of the study. While most of the phones worked well, we observed that some phones ran out of memory and did not record all screens. The screen capture software did for technical reasons not capture the content of video recordings. Hence, information about video recording was based on the recordings the pupils kept on their phones.

The screen capture software ran in the background and slightly affected the stability of the system software. From time to time, this resulted in some of the phones freezing (every few days). In this case children rebooted the phones, but their task was interrupted.

As phones may be passed between people, we have no information whether or not others used the phone. During school time this was to our knowledge very rare, as all children had their phone available. For use at home we are less certain as parents, siblings, or friends may have used the phones, too.

Concerns about abuse and misuse of the technology were prevalent among the parents. The software for taking screenshots, initially designed as research tool, served a second purpose: supervision. As children knew their actions were monitored, we did not observe inappropriate use. However we did not explore this issue in detail and it remains to further research to investigate how effective and acceptable monitoring can be realized, without violating the need for private spaces in the use of mobile technologies.

\section{CONCLUSION}

In this paper we investigated the adoption of mobile phones by children in rural Panama. Our goal was to understand the impact of using mobile phones both as educational tools on teaching and learning and for recreational use beyond the novelty effect. We provided 23 pupils with touchscreen phones over the course of 20 weeks.

During the study there was almost no interference by the researchers and the data was collected automatically by capturing screenshots every $20 \mathrm{~s}$. Over the course of the study more than 1.5 million screenshots were taken and analyzed in parts. Using this logging approach, we were able to investigate user habits and their use of technology. In contrast to other methods (e.g., direct observation), this approach allowed an unobtrusive observation with a comparably low effort and without observers being present. Having no observer present 
during the experiment and running a long-term study, we think that this approach allows a higher validity of the results and will be interesting for other research projects that want to explore new fields with a similar methodology in educational contexts. Since the pupils were also allowed to take the phones home with them, our observation also reveals insights into how children in Panama adopt mobile phone usage.

Our research is an example of how to study emerging technology use over a longer term. During the experiment, we did neither enforce certain usage patterns (e.g., by providing tailored educational applications or content) nor did we prescribe how the phones should be used. It was deliberately set up so that the teacher and pupils could use the phone in ways they considered useful for teaching/learning and beneficial. Our analysis showed that pupils used the phones for different subjects and tasks during their lessons at school. It was exciting to see the how well the participants could appropriate the devices for the use even if they had only little/no prior knowledge.

Another finding of our research is that mobile phones even without specific learning applications empower teachers to create learning activities in the way they are used to teach. We see this approach similar to providing students with pen and paper where the versatility of the tool (pen/paper/phone) actually supports the teaching and learning process.

Most prominent use cases were accessing the Internet using the phone as a camera, as a playback devices, or as a replacement for copying machines. Having the phones available at all times allowed the teacher to spontaneously make use of information available on the Internet and enabled him to give different task to students and hence to differentiate based on the pupils ability. Through interviews with the teacher, children, and guardians we learned about a strong motivational effect of using phones as educational tool. This effect lasted over the duration of the entire study. Overall our results suggest that mobile phones are a versatile and powerful tool that can be used across a wide range of subjects.

\section{ACKNOWLEDGEMENTS}

This project was partly funded from the German Research Foundation within the Cluster of Excellence in Simulation Technology (EXC 310/1) at the University of Stuttgart.

\section{REFERENCES}

1. Bell, M., Chalmers, M., Barkhuus, L., Hall, M., Sherwood, S., Tennent, P., Brown, B., Rowland, D. Benford, S., Capra, M., and Hampshire, A. Interweaving mobile games with everyday life. In Proc. CHI '06, ACM (New York, NY, USA, 2006), 417-426.

2. Dangwal, R., and Kapur, P. Children's learning processes using unsupervised "hole in the wall" computers in shared public spaces. Australasian Journal of Educational Technology 24, 3 (2008), 339-354.
3. Ford, M.; Leionen, T. A mobile tool and service framework for formal and informal learning. In mLearn 2006, AU Press (2006), 195-214.

4. Frohlich, D. M., Rachovides, D., Riga, K., Bhat, R., Frank, M., Edirisinghe, E., Wickramanayaka, D., Jones, M., and Harwood, W. Storybank: Mobile digital storytelling in a development context. In Proc. CHI '09, ACM (New York, NY, USA, 2009), 1761-1770.

5. Hollow, D., and Masperi, P. An evaluation of the use of ict within primary education in malawi. In Proc. ICTD '09 (April 2009), 27-34.

6. Jain, M., Birnholtz, J., Cutrell, E., and Balakrishnan, R. Exploring display techniques for mobile collaborative learning in developing regions. In Proc. MobileHCI '11, MobileHCI '11, ACM (New York, NY, USA, 2011), 81-90.

7. Jarkiewicz, P., Frankhammar, M., and Fernaeus, Y. In the hands of children: Exploring the use of mobile phone functionality in casual play settings. In Proc. MobileHCI '08, ACM (New York, NY, USA, 2008), 375-378.

8. Kam, M., Kumar, A., Jain, S., Mathur, A., and Canny, J. Improving literacy in rural india: cellphone games in an after-school program. In Proc. ICTD '09 (April 2009), 139-149.

9. Kam, M., Mathur, A., Kumar, A., and Canny, J. Designing digital games for rural children: A study of traditional village games in india. In Proc. $\mathrm{CHI}$ '09, CHI '09, ACM (New York, NY, USA, 2009), 31-40.

10. Kumar, A., Tewari, A., Shroff, G., Chittamuru, D., Kam, M., and Canny, J. An exploratory study of unsupervised mobile learning in rural india. In Proc. CHI '10, CHI '10, ACM (New York, NY, USA, 2010), 743-752.

11. Mathur, A., Ramachandran, D., Cutrell, E., and Balakrishnan, R. An exploratory study on the use of camera phones and pico projectors in rural india. In Proc. MobileHCI '11, ACM (New York, NY, USA, 2011), 347-356.

12. Nokia. Momath nokia mobile mathematics. https: //projects . developer.nokia.com/Momaths/, 092013.

13. Reitmaier, T., Bidwell, N. J., and Marsden, G. Field testing mobile digital storytelling software in rural kenya. In Proc. MobileHCI '10, MobileHCI '10, ACM (New York, NY, USA, 2010), 283-286.

14. Valderrama Bahamondez, E. d. C., Winkler, C., and Schmidt, A. Utilizing multimedia capabilities of mobile phones to support teaching in schools in rural panama. In Proc. CHI '11, ACM (New York, NY, USA, 2011), 935-944. 